\title{
LAS OTRAS EN LOS DERECHOS HUMANOS
}

\author{
MERCEDES ALCAÑIZ \\ Universitat Jaume I. Castellón
}

\section{INTRODUCCIÓN}

La Modernidad instauró la igualdad (y la libertad) como uno de sus fines principales. La proclamación de la Independencia Americana de $1776^{1}$ y la Declaración de Derechos del Hombre y del Ciudadano de 1789 consagraron estos principios como ejes ideológicos sobre los que se articularía la organización normativa de la sociedad occidental moderna.

Las primeras declaraciones incluían una idea de universalidad que posteriormente fue delimitándose a ciertos colectivos con características sexuales (hombres), raciales (blancos) y sociales (propietarios), por lo que el ideal preliminar universalista dejaba bastante que desear.

A lo largo del siglo XIX se configuraron movimientos sociales reivindicativos exigiendo el cumplimiento de los principios proclamados en la Revolución: entre ellos se encuentran los movimientos de liberación nacional, el movimiento obrero, el movimiento anti-esclavista y el movimiento feminista en su primera ola, conocido también como movimiento sufragista.

En lo que respecta al movimiento feminista, en sus primeros momentos, sus objetivos se centraban en la consecución del derecho al voto para las mujeres. Objetivo que se fue cumpliendo en la mayor parte de los países con posterioridad a la Primera Guerra o a la Segunda Guerra Mundial2.

Ahora bien, el principio de igualdad aplicado a los sexos no se reconoció hasta la Declaración Universal de Derechos Humanos de 1948, Declaración no

1. Anterior a la Declaración Americana de 4 de Julio de 1776 fue la Declaración del Buen Pueblo de Virginia de 12 de Junio de 1776.

2. Los primeros países en conceder el voto a las mujeres fueron Nueva Zelanda y Australia. En Europa, el primero fue Finlandia en 1906. Antes de la Gran Guerra, los países con derecho al voto para las mujeres eran Dinamarca, Austria, Estonia, Polonia, Alemania, Reino Unido, Luxemburgo, Países Bajos y Suecia. Entre 1920 y 1945, República Checa, Eslovaquia, Lituania, España (derogado posteriormente), Bulgaria, Francia, Hungría, Italia, Eslovenia y después de la Segunda Guerra, Bélgica, Grecia, Chipre, Portugal y España. 
vinculante, pero que ha tenido una fuerza moral influyente en la redacción de las Constituciones u otros instrumentos jurídicos estatales, constituyendo estos derechos en fundamentales.

La Igualdad fue, pues, el principio básico que estructuró la sociedad posterior a la Segunda Guerra Mundial y que obligó a los Estados a modificar toda su jurisprudencia en aras de aplicar el principio de igualdad y el de no discriminación entre los géneros.

Desde hace un par de décadas aproximadamente, comenzaron a surgir digresiones con respecto de la idea de igualdad entre los géneros: así, el feminismo de la diferencia reivindicó la diferencia (que no desigualdad) entre hombres y mujeres. La Razón Universal de la Modernidad empezaba a ser cuestionada y los principios proclamados por la teoría post-moderna comenzaban a ganar adeptos: dicha corriente teórica ${ }^{3}$ se identifica con el rechazo al universalismo racionalista y a una noción de sujeto como categoría universal ${ }^{4}$.

Básicamente, la noción de diferencia aparece como respuesta a las teorías cuyos conceptos son caracterizados como universales y que presuponen un modelo de ser humano con ciertas características homogéneas o universales. El término diferencia, por el contrario, apela a aquellas características que distinguen a las personas, a sus rasgos particulares o singulares, a la heterogeneidad en vez de la homogeneidad.

Aplicados estos principios a los Derechos Humanos, se exige a éstos el reconocer que las mujeres son diferentes, por lo que se debe tener en consideración Derechos Humanos que les atañen exclusivamente a ellas por sus particulares diferencias. Se hace necesario, pues, una reformulación global de los DH con perspectiva de género porque la realidad práctica evidencia que los instrumentos nacionales e internacionales y los mecanismos de $\mathrm{DH}$ a menudo hacen invisibles las necesidades, deseos y demandas de las mujeres ${ }^{5}$.

\section{LAS OTRAS 6 EN LAS PRIMERAS DECLARACIONES DE DERECHOS HUMANOS: RELATO DE UNA AUSENCIA}

Es de sobra conocido que la Revolución Francesa supuso una ruptura radical con respecto a la sociedad existente con anterioridad, denominada Sociedad Feudal o Antiguo Régimen ${ }^{7}$.

3. LYON, D. : Postmodernidad, Alianza. 1994.

4. Ahora bien, no caigamos, como señala Lola García Luna (GARCÍA LUNA, L.: La historia feminista del género y la cuestión del sujeto. http://www.mujeresenred.net/f-lola_luna-sujeto.html, 2002, p. 4), en construir un sujeto universal «mujer». Lo que apunta el posmodernismo es la pluralidad de sujetos históricos contextualizados, representados por múltiples grupos de mujeres y hombres, frente al sujeto universal abstracto del discurso de la modernidad que remitía finalmente a un sujeto hegemónico masculino.

5. GARCIA INDA y LOMBARDO: Género y Derechos Humanos, Mira Editores, 2002.

6. Tomo este término de Simone de Beauvoir quien lo utilizó en su libro «El Segundo Sexo» para describir la situación de las mujeres en la sociedad. Considero que esta denominación explicita el contenido de este punto.

7. Hay mucha bibliografía escrita sobre la Revolución Francesa. En este punto he seguido el libro La Revolución Francesa y el Imperio (1787-1815) de Georges LEFEBVRE, FCE, 1995. 
La mutación histórica que supuso el acontecimiento revolucionario, en cuanto a la organización y estratificación social (abolición de los estratos y privilegios de la nobleza), se considera como uno de los cambios más trascendentales ocurridos en la historia de la humanidad. Esta transformación, aunque dirigida y promovida por la clase burguesa, estuvo apoyada por otros grupos sociales integrantes del denominado Tercer Estado y también, no hay que olvidarlo, por las mujeres, olvidadas una vez más por los que escribieron posteriormente la historia ${ }^{8}$, en su mayoría hombres del grupo de los triunfadores, los cuales impusieron su propia visión de los hechos y de los acontecimientos.

Las agitaciones existentes en dicho ambiente revolucionario, hicieron replantearse a buen número de mujeres su posición y su lugar en la sociedad, si bien sus exigencias y sus ansias de entrar en pie de igualdad con respecto de los hombres en las recientes conquistas fueron rápidamente frenadas por sus compañeros varones ${ }^{9}$.

La nueva sociedad surgida de la Revolución tenía que articular y construir un nuevo sistema de géneros. Las mujeres, por lo que les concernía en su propia piel, querían que el cambio acaecido se plasmase en una nueva relación entre los sexos; los hombres no lo tienen tan claro (o nada claro) y finalmente optan por la solución más conservadora, la de que no se altere la situación de primacía del varón sobre la mujer, considerada incluso por los propios ilustrados como la «situación natural».

Bonald lo decía así de explicito:

"La mujer es súbdito y el hombre poder. No se puede alterar la relación entre los sexos por una decisión política ${ }^{10}$.

Durante todo el período revolucionario, las mujeres participaron en las sublevaciones espontáneas u organizadas pero no participaron en las deliberaciones de las asambleas públicas, tuvieron que crear sus propias Tribunas abiertas al público y sus propios clubes como La Sociedad patriótica y de Beneficencia de las amigas de la verdad (1791-1792) y el Club de Ciudadanas Republicanas Revolucionarias $(1793)^{11}$.

La Declaración de los Derechos del Hombre y del ciudadano de 1789 manifiesta de forma clara, en su Art 1 :

"Los hombres nacen y permanecen libres e iguales en derechos. Las distinciones sociales sólo pueden fundarse en la utilidad común».

8. Desde la vertiente post-moderna, el relato histórico se denuncia como un relato sesgado por la perspectiva patriarcal, una historia escrita con pretensiones de universalidad que en realidad oculta la diferencia, la particularidad de la perspectiva femenista (BELTRÁN, E. Y MAOUIEIRA, V. (eds): Feminismos. Debates teóricos contemporáneos, Alianza Editorial, Madrid, 2001, p. 255).

9. FRAISSE y PERROT: Historia de las Mujeres. El siglo XIX, Círculo de Lectores, 1994.

10. FRAISSE y PERROT, ibíd., p.42.

11. FRAISSE y PERROT, ibíd., p.28. 
Esta ausencia o exclusión del término mujeres, da pie a que dos años después, Olimpe de Gouges escriba y publique «La Declaración de los Derechos de la Mujer y de la Ciudadana $»^{12}$ modificando la redacción del Art 1 de la siguiente manera:

"La mujer nace libre y permanece igual al hombre en derechos. Las distinciones sociales sólo pueden fundarse en la utilidad».

El que los hombres no tuvieran claro las exigencias de cambio en la situación de las mujeres, nos lo manifiesta el hecho de que Gouges fuera guillotinada en 1793 por sus compañeros varones de la Revolución.

También Condorcet, ilustrado conocido, escribió en defensa de las mujeres con su artículo "Sobre la admisión de las mujeres al derecho de ciudadanía» (1790), y Madame de Cambis: «Del destino actual de las mujeres» (1791). También en los "Cahiers de doleances»" ${ }^{13}$ se incluían numerosas reivindicaciones anónimas pidiendo que las mujeres pudiesen formar parte del gobierno y tener representación en la Asamblea Nacional.

Desde un punto de vista político, Gouges en su art 3 incluía:

»El origen de toda soberanía reside esencialmente en la nación, que no es más que la reunión de hombres y mujeres».

Con esto quería decir que una Constitución es nula si no participa también la mujer. También Mary Wollstonecraft por las mismas fechas (1791) le escribe una carta el Ministro Talleyrand recordándole que «excluir a la mitad de la raza humana en toda participación política en el gobierno es un fenómeno político que no puede verse justificado en nombre de principios abstractos ${ }^{14}$.

Cuestiones que serían obvias dos siglos después, se consideraron propuestas revolucionarias y desestabilizadoras del sistema de géneros imperante en la época.

Así pues, la Revolución Francesa lo mismo que la Americana, abren la puerta de la igualdad jurídica como derecho del individuo, basado en la tradición cristiana y del derecho natural pero, y esto es importante, no aclara explícitamente que esta igualdad incluya a las mujeres y dada su situación jurídica y social confusa, habrá que esperar muchos años para que la igualdad proclamada en los textos revolucionarios se haga realidad para la totalidad de las mujeres.

La igualdad liberal, iniciada a partir de este momento, se predica universalista, y sin embargo, se trata de un falso universalismo ${ }^{15}$.

12. Este texto denuncia la falsa universalidad del término hombre aplicado a los derechos y recuerda que estos también tienen que declinarse en femenino (Beltrán, op.cit., p.19).»Hombre» no es sinónimo de Humanidad.

13. Sobre este tema recomiendo la lectura del libro 1781-1793. La voz de las mujeres en la Revolución Francesa. Cuadernos de Quejas y otros textos, La Sal edicions de les dones, Institut Valencia de la Dona, 1984.

14. WOLLSTONECRAFT, M.: Vindicación de los Derechos de la Mujer, Debate, 1998.

15. Norberto Bobbio ha señalado que en la famosa proclama de la Declaración francesa, el significado revolucionario proviene del término «todos» ya que se contraponía a la situación del Antiguo 
La consideración de la mujer como "menor jurídica» y dependiente, como siempre, del hombre marido o padre, se contempla en el conocido Código Civil de $1804^{16}$ promulgado por Napoleón e imitado posteriormente en otros países europeos. Este texto, manifiesta, desde el punto de vista legal, el reflejo de la idea de patriarcado como sistema de géneros prevaleciente a partir de entonces, así como la construcción del rol de género que se le iba a imponer a la mujer, olvidando todos los escarceos revolucionarios realizados por las mujeres con el objetivo de intentar conseguir un "puesto» en la sociedad recién creada.

La Declaración de los Derechos del Hombre y del Ciudadano, que incluía principios vinculados a los derechos civiles y políticos, quedará plasmada en las Constituciones de los distintos países europeos desde principios del siglo XIX. Veremos a continuación cómo se reflejó este ideario liberal, universal en teoría pero excluyente en la práctica, en las Constituciones del siglo XIX español.

En 1812, una vez expulsados los franceses de territorio español se reunieron las Cortes en Cádiz y se promulgó la primera Constitución Española ${ }^{17}$ conocida como la Pepa.

Esta Constitución supone la entrada de España en el ámbito del liberalismo constitucional y su ruptura con el Antiguo Régimen ya que echaba por tierra todos los privilegios de la nobleza y otros estamentos previos, suprimiendo las jurisdicciones señoriales, la Inquisición, los gremios y proponiendo la secularización de las órdenes religiosas, el reparto de las tierras baldías y comunales.

Su objetivo, como continuadora del espíritu de la Revolución de 1789, era proteger por Ley la libertad civil, la propiedad y los demás derechos legítimos de todos los individuos. ¿Incluía esto a las mujeres? No lo parece, a tenor de lo expresado en algunos puntos concretos de la Constitución que manifiestan la consideración que en la época se tenía sobre las mujeres:

En el Cap II De los españoles, el art 5 indica quiénes son españoles y textualmente dice lo siguiente:

«Todos los hombres libres nacidos y avecindados en los dominios de las Españas y los hijos de éstos».

El ejercicio de los mismos derechos se suspende por: incapacidad física o moral, por deudor, por sirviente doméstico ${ }^{18}$, por no tener empleo, oficio o modo de vivir conocido, por hallarse procesado, y a partir de 1830 deberán saber leer y escribir.

Régimen en donde no todos disfrutaban de bienes y derechos. Ahora bien, este "todos» no incluía a las mujeres porque se consideraba que las Mujeres no tenían Razón, que estaban más vinculadas a la Naturaleza.

16. FRAISSE Y PERROT, op.cit., pp. 92 y ss.

17. Anteriormente se elaboró la Constitución de Bayona de 1808 bajo la autoridad de José Bonaparte.

18. Aunque prioritariamente eran más las mujeres dedicadas al servicio doméstico, también trabajaban hombres como sirvientes. Dice Asunción Ventura (Las mujeres en la Constitución Española, Instituto de la Mujer, Madrid, 1999, p. 75) que este trabajo se consideraba denigrante para los varones hasta el punto de acarrear la suspensión de derechos. 
Obvio es decir que ¡cómo podían ser ciudadanas las mujeres si un gran porcentaje se dedicaba al servicio doméstico, la mayoría no tenían oficio ni empleo y por supuesto eran las menos las que sabían leer y escribir?

Con respecto de los Derechos Políticos, el texto de la Constitución no excluye explícitamente a las mujeres de poder ser elegidas pero las condiciones que incluye para ello alejan al sexo femenino de la posibilidad. Así lo expone el Art 91:

«Para ser diputado de Cortes se requiere ser ciudadano que esté en el ejercicio de sus derechos, mayor de 25 años....»

Y además, el Art 92:

«Se requiere además, para ser elegido diputado de Cortes, tener una renta anual proporcionada, procedente de bienes propios»

En resumen, la Constitución liberal de 1812, progresista con respecto a la época anterior e instauradora del Estado liberal en España y del espíritu de la revolución con la defensa de los derechos civiles y políticos, individuales, no hace ninguna referencia a la igualdad entre los sexos, ni consideración alguna que haga presuponer que las mujeres son también objeto de derechos como los hombres. No es raro teniendo en cuenta que en España el peso de la Iglesia y de la tradición eran mayores que en Francia, por lo que es hasta cierto punto lógico que los pro-hombres de la Constitución ni pensaran en el detalle, más bien si alguien se lo hubiera sugerido lo hubieran encontrado una osadía.

El siglo XIX fue un siglo pródigo en constituciones ${ }^{19}$, en todas ellas se va perfilando la inclusión de los derechos individuales, o de primera generación, de forma especial los que hacen referencia a la libertad, la propiedad y la igualdad, en este caso una "igualdad» limitada a ciertos sectores varoniles de la sociedad.

Fue el Proyecto de Constitución Federal de la I República Española de 1873, la primera Constitución que incluía, además de los derechos individuales enumerados en las anteriores, la igualdad ante la ley, y por primera vez se incluye que el ejercicio de todos los cultos es libre en España (art 34) y que las actas de nacimiento, de matrimonio y defunción serán registradas siempre por las autoridades civiles (art 38).

Los deseos universalistas expresados en la Declaración Francesa y en las Constituciones que la siguieron no fueron tales, ya que además de las mujeres se excluían de la posibilidad de ejercer su derecho al voto a los hombres que no contaran con propiedades.

19. Después de la de 1812, se aprobó la Constitución de la Monarquía Española de 18 de Julio de 1837: en ella el artículo $1^{\circ}$ cambia la redacción con respecto a la del 1812 ya que define como españoles a «Todas las personas....». También hay otra Constitución de la Monarquía Española de 1845, la No promulgada de 1856, la de 1869, y después del Proyecto de Constitución Federal de la I República Española, la de 1876 con la Restauración de la Monarquía . 
Hasta la Ley de 1890 que concedió el Sufragio Universal masculino, el régimen liberal censitario otorgaba el Derecho de Sufragio solamente a las siguientes categorías económico-sociales (Art 15 de la Ley electoral de 1878):

«A los varones mayores de 25 años, que pagasen una cuota mínima al tesoro público de 25 pesetas anuales de contribución territorial, con un año por lo menos de antelación a la consulta electoral próxima; o a los que pagasen una cuota anual de 50 pts en concepto de subsidio industrial, por lo menos durante dos años antes del acto electoral que daba derecho a participar en las elecciones» ${ }^{20}$.

La ausencia reiterada de una referencia a las mujeres en las Declaraciones y en las Constituciones que a lo largo del siglo XIX se fueron promulgando, dio lugar a movilizaciones feministas ${ }^{21}$ organizadas con el objetivo de que se reconocieran los derechos civiles y políticos de las mujeres. Norteamérica y Gran Bretaña fueron los países donde se realizaron más reivindicaciones para conseguir el derecho al voto y el reconocimiento de la mujer como persona jurídica.

\section{EL UNIVERSALISMO SUSTITUCIONALISTA APLICADO EN LOS DERECHOS HUMANOS: LA IGUALDAD ENTRE LOS GÉNEROS}

Concluidos los desastres que a nivel mundial produjo la Segunda Guerra Mundial, se aprobó la Carta de las Naciones Unidas o Carta de San Francisco por ser esta ciudad donde se celebró la conferencia ${ }^{22}$.

Aunque el propósito inicial o básico de la Carta es conseguir la paz y seguridad mundial, se incluyeron otros aspectos entre los cuales destaca el Art 1 punto 3:

«el respeto por los DH y las libertades fundamentales de todos sin hacer distinción por motivos de raza, sexo, idioma o religión» ${ }^{23}$

Observemos que en este punto el término todos especifica que no hace distinción a la raza, al sexo, al idioma o a la religión. Aquí se introduce una diferencia importante con respecto de la Declaración de los Derechos del Hombre y del Ciudadano de 1789.

En el año 1948 se aprobó la Declaración de Derechos Humanos, se elimina el término hombre de la Declaración anterior y se generaliza a humanos ${ }^{24}$, lo cual implica otra diferencia sustancial con respecto de la Declaración del XVIII,

20. MARTÍNEZ CUADRADO, M. : La burguesía conservadora. 1874-1931, Alianza, 1986.

21. En «La Declaración de Sentimientos y Resoluciones de Séneca Falls» (1848), las mujeres norteamericanas afirman que «la mujer es igual al hombre, que así fue establecido por el Creador y que el bien de la raza humana exige que sea reconocida como tal».

22. Entre los antecedentes a la Carta Magna se situaría la Sociedad de Naciones, la Carta Atlántica (Roosvelt y Churchill) de 1941 y la Conferencia de Yalta en Febrero de 1945.

23. DÍEZ DE VELASCO, M.: Las organizaciones internacionales, Tecnos, 2002, pp. 155-163.

24. Si bien, en el Preámbulo de la Declaración, se utiliza por tres veces el término hombre como genérico de hombre y mujer. 
iniciándose así el proceso de afirmación de igualdad entre los sexos y de aplicación de instrumentos jurídicos apropiados para su consecución ${ }^{25}$.

Aunque la Declaración Universal de los Derechos Humanos no ha sido vinculante, tuvo un gran peso moral que influyó en los instrumentos jurídicos estatales, como las Constituciones, recogiendo sus principios y constituyéndolos en Derechos Fundamentales. Señala Diez de Velasco ${ }^{26}$ que la Declaración ha cumplido una función moralizadora básica imprimiendo buena parte de los desarrollos normativos ulteriores en materia de Derechos Humanos tanto a nivel internacional como interno.

La Comisión creada en la ONU para estudiar la situación social y jurídica de la mujer se puso a trabajar para redactar la Convención sobre la Eliminación de la Discriminación contra la mujer, ratificada en 1979 por la Asamblea General y que puede considerarse el primer paso en el reconocimiento internacional de la necesidad de considerar específicamente los derechos de las mujeres como derechos humanos. Los Estados que ratificaron la Convención se comprometieron a ir incluyendo en sus constituciones y demás reglamentos el principio de igualdad y no discriminación ${ }^{27}$.

A propuesta de la ONG finlandesa, Women's International Democratic Federation, la Comisión propuso la organización de una Conferencia Mundial sobre las Mujeres cuya primera celebración tuvo lugar en Ciudad de México en 1975. En esta primera Conferencia se estableció el Plan de Acción Mundial con los siguientes objetivos: aumentar el alfabetismo y garantizar el acceso igualitario a la educación, aumentar las oportunidades de empleo y reducir el desempleo y la discriminación en los términos y las condiciones del empleo, igualdad para el sufragio, la elección y la participación política, paridad en el ejercicio de los derechos civiles, sociales y políticos así como el reconocimiento del valor del trabajo de las mujeres en el hogar, la producción doméstica, la comercialización y otras actividades no remuneradas.

Se declaró el decenio de las mujeres teniendo lugar dos conferencias mundiales más, la de Copenhague en 1980 y la de Nairobi en 1985. En esta última se elaboraron las Estrategias de Nairobi, las cuales, además de incluir las estrategias hacían referencia también a medidas de actuación ${ }^{28}$.

En el ámbito interno de los Estados y concretamente en lo referente al Estado Español, una vez superado el Régimen Franquista, pródigo en conceder ningún tipo de igualdad entre los géneros, fue la Constitución Española de

25. La Declaración de 1948 incluye, además, otra novedad con respecto de las anteriores, la referencia a los Derechos Sociales. Así, los artículos 3 al 21 se centran en los derechos individuales y los artículo 22 al 27 a los derechos sociales.

26. DIEZ DE VELASCO: op.cit., p. 290.

27. Con fecha de año 2000, de los países integrantes de la ONU, 163 han ratificado la Convención, 25 no han firmado ni ratificado y 3 han firmado pero no han ratificado (los Estados Unidos de América).

28. HERNÁNDEZ, I. Y RODRÍGUEZ, A.: Igualdad, desarrollo y paz. Luces y sombras de la acción internacional por los derechos de las mujeres, HEGOA, 1996. 
$1978^{29} 30$ la que recoge los principios expuestos en la Declaración de 1948, concretamente en el Art 10, $2^{\circ}$ :

"Las normas relativas a los derechos fundamentales y a las libertades que la Constitución reconoce, se interpretarán de conformidad con la Declaración Universal de DH y los tratados y acuerdos internacionales sobre las mismas materias ratificados por España».

Los artículos que hacen referencia a la igualdad en la Constitución del 78 son el artículo 1.1., el 9.2 y el 14. Este último se considera básico para la consideración del principio de igualdad «formal»

"Los españoles son iguales ante la ley, sin que pueda prevalecer discriminación alguna por razón de nacimiento, raza, sexo, religión, opinión o cualquier otra condición o circunstancia personal o social».

A través de dichos artículos, se pueden extraer reglas y pautas de comportamiento de los poderes públicos para eliminar las desigualdades ${ }^{32}$ y se inicia el proceso de revisión de la normativa española con el fin de eliminar cualquier resquicio que incluya discriminación entre hombres y mujeres.

El Art 9.2 denominado también como el de la igualdad «real», es el más acorde con los valores que comporta el Estado social y democrático:

"Corresponde a los poderes públicos promover las condiciones para que la libertad y la igualdad del individuo y de los grupos en que se integra sean reales y efectivas; remover los obstáculos que impidan o dificulten su plenitud y facilitar la participación de todos los ciudadanos en la vida política, económica, cultural y social.»

Vemos, pues, cómo, progresivamente, se va consolidando la aceptación de los Derechos Humanos, su plena realización y aplicación de todos los derechos y libertades fundamentales a las mujeres, si bien sobre este aspecto surgen desde la teoría feminista ciertos reproches por sus pretensiones universalistas, que sólo pretenden incluir a las mujeres en lo dado, sin considerar su experiencia propia.

Así, desde la teoría crítica feminista ${ }^{33}$, Sheila Benhabib distingue entre un universalismo sustitucionalista, que define como el universalismo que identifica las experiencias de un grupo específico de sujetos (en general, hombres blancos propietarios) como paradigmático de los humanos, y un universalismo interactivo, que reconoce la pluralidad de modos de ser humano, diferenciando entre las

29. No hay que olvidar que la Constitución de la II República de 1931 incluía en su artículo 25 «No podrán ser fundamento de privilegio jurídico: la naturaleza, la filiación, el sexo, la clase social, la riqueza, las ideas políticas ni las creencias religiosas».

30. Por otra parte, preciso es señalar que esta Constitución sólo cuenta con «Padres» (ponentes). Una vez más el origen del Estado es un «acto» de los varones sin contar para nada con las mujeres.

31. VENTURA, A.: Las mujeres en la Constitución Española, Instituto de la Mujer, 1999.

32. Excepción al principio de igualdad es el Art 57.1 sobre la preferencia del varón sobre la mujer para heredar la Corona Española.

33. BENHABIB, S.: Teoría Feminista y Teoría Crítica, Alfons el Magnànim, 1990. 
personas sin inhabilitar la validez moral y política de todas estas pluralidades y diferencias.

Esta autora (y otras) trata de mostrarnos que ignorar el punto de vista del otro concreto, nos lleva a incoherencias morales epistémicas en las teorías morales universalistas ${ }^{34}$.

Desde el análisis realizado a las Declaraciones y Constituciones en lo referente a la igualdad entre los géneros, concluimos que hasta estas fechas se ha aplicado una óptica universalista sustitucionalista en el sentido de que se ha pretendido integrar a las mujeres en la tradición universalista, sujetos abstractos, anulando la existencia de sujetos específicos, las mujeres, las cuales exigen un trato diferente basado en sus diferencias innatas. Veremos los resultados de este debate en el siguiente punto.

\section{3.-EL RECONOCIMIENTO: LA APLICACIÓN DE LA PERSPECTIVA DE GÉNERO EN LOS DERECHOS HUMANOS}

En el período final del siglo XX, se desarrolla un nuevo imaginario político que toma como ejes las ideas de identidad, diferencia o reconocimiento. Todo ello en un marco teórico de nuevo paradigma, como es el pensamiento posmoderno ${ }^{35}$.

Este replanteamiento de las principales aportaciones que realizó la Ilustración en su momento, cuestiona varias ideas que se perseguían con anterioridad por el movimiento feminista entre ellas, la universalidad del sujeto único (varón blanco y rico).

El feminismo de la diferencia influido por las ideas postmodernas, reivindica la diferencia, lo particular, en definitiva el reconocimiento de las identidades, de que la igualdad no puede construirse como semejanza "con respecto de» sino como reivindicación de la diferencia.

Como señala Nancy Fraser, las reivindicaciones del reconocimiento de la diferencia estimulan la lucha de grupos que se movilizan bajo la bandera de la nacionalidad, la etnicidad, la raza, el género, la sexualidad etc

Las apelaciones al reconocimiento tienden a promover las diferencias de grupo al reivindicar el valor de las especifidades que les prestan una identidad, rechazando contrariamente, la universalidad, la existencia de un sujeto único.

Desde la perspectiva de la reivindicación de la diferencia se va a reivindicar el reconocimiento de las particularidades de las mujeres en el contexto de los derechos humanos.

En 1993 se celebra en Viena, la Conferencia sobre Derechos Humanos y se proclama la promoción de los $\mathrm{DH}$ y su protección. Se inicia una nueva línea en la consideración de los $\mathrm{DH}$ y el género ${ }^{36}$ ya que la violencia de género pasa a

34. BELTRÁN, E et alii : Feminismos. Debates teóricos contemporáneos, Alianza, 2001.

35. Dice Celia AMORÓS (Tiempo de Feminismo. Sobre feminismo, proyecto ilustrado y posmodernidad, Feminismos/Cátedra, Madrid, 1997, p. 335) que «la posmodernidad quiere deconstruir lo universal para que emerja el reino de las diferencias".

36. En Viena se proclamó de forma oficial que «la participación plena de las mujeres, en condiciones de igualdad, en la vida política, cívica, económica, social y cultural, en los niveles nacional, 
considerarse como una violación de los DH de las mujeres haciendo responsable a los Estados de su eliminación ${ }^{37}$.

En Viena se reunieron representantes de los 171 países miembros; en el fórum paralelo de ONG, se organizó un tribunal para juzgar violaciones de derechos de las mujeres con el objetivo de demostrar, a través de muchos casos dramáticos, que los mecanismos de protección de los derechos humanos existentes no consiguen actuar en muchas situaciones.

En la Declaración de DH en 1995, con motivo del 50 aniversario de las Naciones Unidas, se aprobó la Resolución 50/6 de la Asamblea General en cuya parte dispositiva se declara:

«Punto 9.- Igualdad de Derechos de Hombres y de Mujeres. Reafirmación de todos los DH son universales, indivisibles e interdependientes».

Esta Declaración incluye el compromiso de los Estados en fortalecer las leyes, las políticas y los programas que garanticen la plena participación de las mujeres en condiciones de igualdad, en todas las esferas de la vida política, civil, económica, social y cultural.

En la IV Conferencia Mundial de las mujeres celebrada en 1995, en Pekín, la Plataforma de Acción Mundial dedica el punto I a «Los Derechos Humanos de las mujeres» reafirmando en ella la Declaración y Programa de Acción de Viena (1993):

«Los Derechos humanos de la mujer y de la niña son parte inalienable, integrante e indivisible de los derechos humanos universales. El disfrute pleno y en condiciones de igualdad de todos los derechos humanos y las libertades fundamentales por la mujer y la niña constituye una prioridad para los gobiernos y las Naciones Unidas y es esencial para el adelanto de la mujer (punto 213)»

Además, en este punto se incluye también: a) referencias explícitas a su protección en la práctica nacional como son los códigos de familia, civiles, penales, laborales y comerciales y en las reglamentaciones administrativas. b) falta de sensibilidad de los órganos judiciales respecto de los derechos humanos de la mujer. c) las mujeres y las niñas sufren discriminaciones en la asignación de recursos económicos y sociales, lo que constituye una violación directa de sus derechos económicos, sociales y culturales. d) promover una política activa y visible encaminada a incorporar una perspectiva de género en todas las políticas y los programas de manera que, antes de que se adopten decisiones, se analicen los efectos que han de tener para los hombres y las mujeres ${ }^{38}$.

regional e internacional, así como la eliminación de todas las formas de discriminación con base en el sexo, constituyen objetivos prioritarios de la comunidad internacional» (VICENTE, A.:Os poderes das mulheres, os poderes dos homens, Gótica, Lisboa, 2002, p. 268).

37. La normativización internacional de la violencia contra las mujeres en razón de su sexo fue ampliada en la Convención Interamericana para Prevenir, Sancionar y Erradicar la Violencia del 1994, también llamada Convención de Belem do Pará.

38. IV Conferencia Mundial sobre las Mujeres, 1996, pp. 579-601. 
Con motivo de la celebración del 50 aniversario de la Declaración Universal, surgieron distintos movimientos que reivindicaban la posibilidad de modificar algunos artículos de la Declaración con el objetivo de hacer más explícito las exigencias diferentes de los derechos de las mujeres (y de otras colectividades). Para ello se basan en que el concepto de derechos humanos es de naturaleza histórica y que su surgimiento ha estado fuertemente asociado a una idea de ser humano centrada en la imagen del varón, occidental, heterosexual y propietario; urge ahora el reconocimiento de la diferencia.

Junto con esta reivindicación de distintos colectivos con distintas identidades y necesidades, se exige también la inclusión de aquellos derechos denominados de tercera generación y que están vinculados a derechos a personas colectivas, a la paz, al desarrollo, al medio ambiente, a la autodeterminación, a la identidad cultural, etc.

En el Proyecto presentado por el Comité de América Latina y el Caribe (CLADEM) para la Defensa de los Derechos de las Mujeres como Derechos Humanos para el siglo XXI se propone incluir el siguiente punto:

"La discriminación contra la mujer niega y limita sus derechos humanos y constituye una violación a la dignidad humana». (Ciudadanía, Art I, punto 3).

\section{Y también:}

"Todas las formas de violencia contra la mujer constituyen atentados a sus derechos humanos fundamentales y a su plena integración al desarrollo social y económico» (Derecho a una vida libre de violencia y a la paz, Artículo I, punto 1).

No podemos olvidar la referencia a los Derechos sexuales y reproductivos:

"Los derechos reproductivos se fundamentan en el reconocimiento del derecho básico de los individuos de decidir libre e informalmente sobre su vida reproductiva y ejercer el control voluntario y seguro de su fecundidad. Los derechos reproductivos incluyen el derecho de mujeres y hombres de tomar decisiones en el campo de la reproducción, libres de discriminación, coerción y violencia, así como el derecho de disponer de los niveles más altos de salud sexual y reproductiva». (Derechos sexuales y reproductivos, artículo I. punto 1).

El 50 Aniversario de la Declaración Universal de los Derechos Humanos significa para la Comunidad internacional la posibilidad de renovar el concepto normativo de los derechos humanos, reconociendo las condiciones desiguales entre hombres y mujeres como motivo para que las mujeres no disfruten plenamente de sus derechos humanos, lo que constituye, en última instancia, una violación a su dignidad humana.

\section{CONCLUSIONES}

Expuesto el proceso histórico en el que se han desarrollado los derechos humanos y más concretamente, la situación de las mujeres en ellos, concluimos que pueden establecerse tres momentos, a modo de fases o etapas, en dicha relación: 
En la primera fase las mujeres son inexistentes, no se consideran sujetos de derechos humanos. Carecen, sobre todo las mujeres casadas, de derechos civiles y políticos; su situación está vinculada a la concepción que entonces se tenía de la mujer como alguien carente de Razón, dominada por las emociones y carente de autonomía como sujeto, ya que se la hace depender para todo del varón (sea padre o marido). La invisibilidad de las mujeres en esta época, queda reflejada en la poca o nula consideración que se tiene hacia ellas en las Constituciones europeas del siglo XIX. Queda patente y manifiesto que el ciudadano por excelencia, el sujeto universal de derechos, es un hombre y además un hombre propietario (por supuesto blanco ya que la esclavitud no se abolió hasta mediados del siglo XIX). Es en este contexto donde cuadra bien la denominación apuntada por Simone de Beauvoir de «las otras».

En un segundo momento, el objetivo prioritario se sitúa en conseguir la igualdad de las mujeres con respecto del hombre en todos los aspectos legales y formales; se trataría, pues, de sustituir los derechos expresados inicialmente al hombre, como sujeto universal absoluto, a todo el género femenino. Para conseguir este principio universal, la igualdad, se suprimen de las legislaciones internacionales y estatales, toda referencia a la desigualdad entre los géneros, aplicándose, además, en los distintos Estados las denominadas Políticas de Igualdad para conseguir la igualdad entre los hombres y las mujeres. "Ellas», pues, tendrán que ser como «ellos» y tener las mismas oportunidades.

Y finalmente, en la última fase, como consecuencia de las aportaciones expresadas por las teorías post-modernas y por las conceptualizaciones realizadas desde diversas corrientes teóricas feministas, se exige la aplicación de la perspectiva de género en los Derechos Humanos, lo cual quiere decir, negando la universalidad anteriormente proclamada, que se tengan en cuenta las diferencias y particularidades existentes en las mujeres para que, reconociéndolas, sean también sujetos de derecho atendiéndose sus diferencias.

Resumiendo, y para concluir, podemos decir que en la actualidad se está produciendo un proceso de deconstrucción del sujeto universal de la Modernidad para, a partir de ahí, construir nuevos sujetos o grupos con características similares, diferentes entre ellos y con exigencias concretas sobre su condición.

Cómo se incorporarán estas nuevas exigencias en las Declaraciones de Derechos Humanos es algo sobre lo que debemos trabajar con ahínco si queremos que el sujeto universal, hombre blanco propietario, deje de ser el sujeto universal que ha predominado desde finales del XVIII y se reconozcan otras identidades y otros sujetos susceptibles de incorporar sus necesidades en igualdad con las ya existentes.

\section{BIBLIOGRAFÍA}

ADAM, Ma D.: La protección de los Derechos de las Mujeres en una sociedad multicultural. Instituto Andaluz de la Mujer, Córdoba, 2001.

AMNISTÍA INTERNACIONAL : Mulheres e Direitos Humanos, AI, Lisboa, 1995.

AMORÓS, C.: Tiempo de Feminismo. Sobre feminismo, proyecto ilustrado y posmodernidad, Feminismos/Cátedra, Madrid, 1997. 
BELTRÁN, E. Y MAQUIEIRA, V. (eds): Feminismos. Debates teóricos contemporáneos, Alianza Editorial, Madrid, 2001.

BENHABIB, S. Y CORNELLA, D.: Teoría feminista y Teoría crítica. Edicions Alfons el Magnànim, Valencia, 1990.

BEAUVOIR, S.de: El segundo sexo, 2 vols., Cátedra, Universidad de Valencia, Madrid, 2000.

CORNELL, D.: En el corazón de la libertad. Feminismo, sexo e igualdad, Feminismos/Cátedra, Madrid, 2002.

DIEZ DE VELASCO, M. : Las organizaciones internacionales, Tecnos, Madrid, 2002.

FRAISSE, G. Y PERROT, M.: Historia de las mujeres. El siglo XIX, Cïrculo de Lectores, Barcelona, 1994.

GARCIA INDA, A. Y LOMBARDO, E.: Género y Derechos Humanos, Mira Editores, Zaragoza, 2002.

GARCÍA LUNA, L.: La historia feminista del género y la cuestión del sujeto. http:// Www.mujeresenred.net/f-lola_luna-sujeto.html, 2002.

GOUGES, OLIMPE DE : «Declaración de Derechos de la Mujer y de la Ciudadana», Asparkia $n^{\circ} 2$, Universitat Jaume I, Castellón, 1994. http://iteso.mx/ jorgee/seminario/ antologías/género/g-cladem.htm.

HERNÁNDEZ, I. Y RODRÍGUEZ, A.: Igualdad, desarrollo y paz. Luces y sombras de la acción internacional por los derechos de las mujeres, Hegoa, Bilbao, 1996.

PNUD: Informe sobre el desarrollo humano 2000, Mundi Prensa, Madrid, 2000.

LYON, D.: Postmodernidad, Alianza Editorial, Madrid, 1994.

MARTINEZ CUADRADO, M.: La burguesía conservadora (1874-1931). Alianza. Madrid, 1986.

NORMAS POLÍTICAS Tecnos. Madrid, 2001.

VENTURA, A.: Las mujeres en la Constitución Española, Instituto de la Mujer, Madrid, 1999.

VICENTE, A: Direitos das mulheres/Direitos humanos, CIDM, Lisboa, 2000.

- Os poderes das mulheres, os poderes dos homens, Gótica, Lisboa, 2002

WOLLSTONECRAFT, M.: Vindicación de los derechos de la mujer, Edición Abreviada, Debate, Madrid, 1998. 